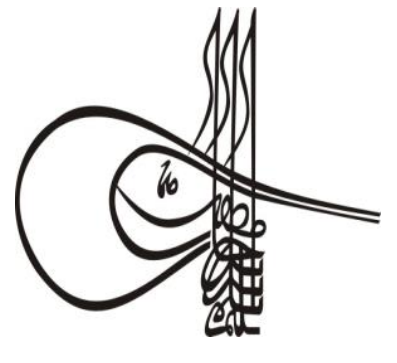

Received/Geliş: 21.08.2019
Turkísh Studies

Volume 14 Issue 7, 2019, p. 4059-4070

DOI: 10.29228/TurkishStudies.30291

ISSN: 1308-2140

Skopje/MACEDONIA-Ankara/TURKEY

Research Article / Araşttrma Makalesi

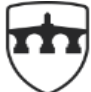

INTERNATIONAL

BALKAN

UNIVERSITY

EXCELLENCE FOR THE FUTURE IBU.EDU.MK

Article Info/Makale Bilgisi

Go Report Dates/Rapor Tarihleri: Referee 1 (26.09.2019)-Referee 2 (24.12.2019)

This article was checked by iThenticate.

\title{
ORTA ASYA TÜRK HALKLARINDA KADİM BİR ATLI SPOR: UKURUK SALMAKTUU- QURIK- EMDİK ÜREDIŞ๋*
}

\author{
Mehmet TÜRKMEN** Kanat DJANUZAKOV ${ }^{* * *}$
}

\section{ÖZ}

Amaç: Bu çalışmada Türk halklarının Orta Asya bozkırlarında yabani ve yarı yabani atları yakalayarak ehlileştirme iş eyleminden kaynaklanan geleneksel atlı spor incelenecektir. Üç dönüşüm ve oluşum geçiren bu sporun ilk aşaması "Ukuruk-Salmay", ikinci aşaması "Qurık" ve üçüncü aşaması "Emdik-Ürediş”tir. Oyunun bu son adını Altay Türkleri 30 yıldır (1988-2018) her çiftli yıllarda bir yaptıkları "El-oyun" festivalinde resmî olarak kullanmaktadırlar. Bu oyuna bașından buyana iştirak eden Tuva, Hakas, Saka Şor, Teleüt, Tofa, Telengit, Telüt, Çulum, Dolgan, Dukha, Sibirya Tararları vb. Sibirya Türk halkları tarafından da biraz değişik lehçelerlede olsa aynı şekilde isimlendirilir.

Yöntem: Literatür taraması yapılmakla birlikte niteliksel yaklaşım içinde yer alan modellerden betimsel araştırma ve karşılaştırma yöntemi kullanılmıştır. Araştırma, Sibirya coğrafyasını da içine alan Orta Asya Türk halklarını kapsamaktadır.

Bulgular: Türk halklarının yabani atı evcilleştirme aşamasında zorunlu olarak ortaya çıkmış, bir atlı oyundur. Dolayısıyla Türk-Moğol halklarının at ile yapılan spor türlerinden ilkidir. Araştırmanın amacı; Türk spor kültüründe baş öneme sahip atlı oyun ve sporları geçirdiği devinimlerle birlikte gün yüzüne çıkarıp, Türk ve dünya spor literatürüne kazandırmaktır.

Sonuç: Geleneksel atl sporun ilk versiyonu ukuruk-salmay, daha ziyade Kırgızların kullandığ ve hala nadir olarak yaylalarda yapmakta olunan bir atlı oyundur. İkincisi qurık, Türk halklarının yaylalara konduklarında iki yaşındaki tayların sırtına ilk eyer koymak için

\footnotetext{
* Bu çalışma, KTMU-BAB-2018.GOSAUM.01 nolu, "Kırgızistan ve Türkiye'de Geleneksel Atlı Sporların Araştırılması" başlıklı projeden üretilmiştir.

** iD Prof. Dr., Muş Alparslan Üniversitesi/Kyrgyz- Turkish Manas University, E-posta: turkmen45.163@gmail.com, turkmenafsin@hotmail.com 
düzenledikleri bir oyun ritüelidir. Üçüncüsü emdik-ürediş ise Sibirya Türk halklarında hala aktif bir yarışma sseklinde yapilmakta olduğu görülmüştür. Bu oyunun kökü insanın çalışma hayatından gelmiş ve sonradan halk eğlencesi ve yarış şeklinde devam etmiştir.

Anahtar Kelimeler: Orta Asya, Türk halkları, Atlı kültür, Atlı spor.

\title{
AN OLD HORSE SPORTS IN CENTRAL ASIAN TURKISH COMMUNITIES: UKURUK SALMAKTYY- QURIKS- EMDIK UREDISH
}

\begin{abstract}
Purpose: This study examines the traditional equestrian sport of Turkish communities arising from the domestication action of catching wild and semi-wild horses in the steppes of Central Asia. The first stage of this sport, which experienced three transformations and formations, is "Ukuruk-Salmay", the second stage is "Qurlk" and the third stage is "Emdik-Uredish". This traditionally sport seems modern Rodeo. This last name of game for 30 years, (1988-2018) every couple of years has been used officially at the "El-oyun" festival by the Altai Turks. Since the beginning this game is named by Tuva, Hakas, Saka Shor, Teleut, Tofa, Telengit, Telut, Chulum, Dolgan, Dukha and Siberian Tatars participants.

Method: In addition to literature review, descriptive research and comparison method was used. The research covers the Turkish peoples of Central Asia including Siberian geography.

Findings: It is an equestrian game that emerged as a necessity during the domestication of the wild horse by Turkish people. Therefore, it is the first type of sport of Turkish-Mongolian people with horses. Purpose of research, the aim of this course is to bring the equestrian games and sports, which have a major importance in Turkish sports, to Turkish and World sports literature.

Conclusion: The first version of the Traditional equestrian sport "Ukuruk-Salmay" is game, which still rarely used in the highlands mostly by the Kyrgyz. Secondly, "Qurık" is a ritual of play organized by two-year old horses to put the first saddle on horseback when Turkish people come to the highlands. Thirdly, "Emdik-Uredish" is still current competition in the Siberian Turkish people. The root of this game came from the working life of the people and later continued in the form of public entertainment and racing.
\end{abstract}

\section{STRUCTURED ABSTRACT}

Purpose of the Study: This study examines the traditional equestrian sport of Turkish communities arising from the domestication action of catching wild and semi-wild horses in the steppes of Central Asia. 
Method: Since this study is produced from the project, the comparison with the descriptive description based on observations rather than the references to the written sources has been taken to the center of this study method. Because the game in question will be watched and observed in its own character, in its own geographies and in its own place. This study conducted within the framework of the field study was limited to the geography of the Turkic peoples of Central Asia.

Results: The historical development of this sport took place at three stages. These were named by Turkish Communities "Ukuruk Salmay" as first, "Qurık" as second and "Emdik Uredish" as third stages. This is an equestrian game that has compulsorily emerged in the domestication stage of wild horses in Turkish Communities. Thus, it was the first horse sport in Turkish-Mongolian Communities. The purpose of this research is to bring the most important equestrian games and in Turkish sports culture together with their historical developmental stages and to bring them into Turkish and world sports literature. In this study, descriptive identification and comparison method was used. The research covers the Central Asia Turkish communities including the geography of South Siberia. As a result; the first version of this traditional equestrian sport is more of a Kyrgyz equestrian game, which is still rarely done in the plateaus. Some of the games played with horse are seen as "Ukuruk Salmay / Salmaktuu, Qurik / Lanky Jalgan and Emdik Urendis". In Kyrgyz Turkish, Ukuruk is referred to as sir a long pole with a looped loop to catch a horse from a herd of wild or semi-wild horses. Qurık / Lanky Jalgan is the first race of 2-3 years old to wear halter and saddle. The sucked Urdish is known as the race for catching wild horses, riding on the saddle and hitting the gem.

Conclusion: It is a play ritual organized by these communities to saddle on the back of two-year-old foals for the first time when they enter the highlands. Thirdly, it is seen that it is still an active competition among the Siberian Turkish communities. These horse catching games of the Turkish peoples are adversely affected due to globalization. For the game to become popular as in the Southern Siberian Turkish peoples, it should be exhibited in Central Asian general and special toys. Scientific pedagogical importance and its cultural role and place should be introduced to the new generations, and the theoretical analysis and practical application of the effectiveness of their plays in the educational process is recommended.

Keywords: Central Asia, Turkish Communities, Equestrian culture, Equestrian sport.

\section{Giriş ve Amaç}

Spor ve kültür alanı, belli bir grubun değerlerini, törenlerini, yaşam biçimlerini ve sporun yaşam tarzındaki yerini ifade eder. Toplum kavramı gibi, kültür kavramı da sosyolojik, antropolojik ve tarihsel bir spor çalışmasında yaygın olarak kullanılmaktadır. Araştırmacı ve öğreniciyi, belirli bir kültürel ortamda oyundaki anlam, sembol, ritüel ve güç ilişkilerini dikkate almaya teşvik eder. Buna ek olarak, birçok ulusal spor türü, hedeflere ulaşmak isteyen gençleri eğitmek, bozkırların doğası ile diğer ulusların kültürünü birleştirmeyi amaçlamaktadır (Jarvie, 2006: 5). Her milletin geçmişten süzülerek gelen, sosyal yapı ve yaşayışlarından kaynaklanan, hatta coğrafi özellikleri de yapısında bulunduran oyun ve spor kültürü anlayışları mevcuttur (Türkmen ve ark., 2006: 77-94). 
Sportif faaliyetlerin insanları eğlendirdiği, hoşça vakit geçirmesini sağladığı, vücutlarının güzel ve estetik görünmesini sağladı gibi, aynı zamanda insanı kendi isteğiyle sportif zorunluluklar uyarınca yönlendirdiği de bir gerçektir. Sporun doğrudan kültürün veya onun her toplumda ayrı şekil ve muhtevada ortaya çıkardığı kültürel yapı elemanlarının tesiri altında yaşadığı söylenebilir. Asya ve Avrupa kültüründe spor farklı olarak algılanır. Asya vücut kültüründeki bilgiler, düşünceler ve uygulamalar daha ziyade toplumların kültürel yaşantılarıyla bir paralellik göstererek dönemler itibariyle farklı şekillerde hayata geçirilmiştir. Asya toplumlarında tabiatın aşıladığı mistik hayat anlayışının, savaş zorluklarının ve filozofça dünya görüşlerinin ortaya çıkardığı kültür o toplumda sporu bedensel ve ruhsal dengesinin sağlanmasında bir araç durumuna sokmuştur ve onun toplumda yaygın bir şekilde kullanılmasını sağlamıştır. Sporun toplum içinde yaygınlaştırılması, fertleri yönlendiren değer yargıları, gelenek ve göreneklerin spor türlerini desteklemesi ile de bağlantılıdır. Örneğin Etrüsklerin yaptıkları sporlar bir kısmı Yunan kökenli sporlar olarak görülebilirse de alfabeleri ve mezarlarında çıkan bazı figürler ise Türk kökenli olduklarını kuvvetlendirir.

Binicilik Avrasya'nın Etnik Profilini Değiştirdi. "At kullanımında bir sonraki büyük değişiklik ata binmeye ve at üzerinde ok-yay kullanmaya başlamak oldu, bu durum bozkıra askeri bir dinamizm kazandırdı ve imparatorlukta ve zapt edilen popülasyonların genetik yapısında sürekli değişimlere yol açtı.”

Türk sanat ve edebiyatında baş öneme haiz olan at ve at yarışları (Uluışı \& Kara, 2018: 100-103) Maalesef, Sovyet yıllarında Türk halkları geleneksel sporları gelişmedi, uygulama yapmadı, geçmişin kalıntıları olarak anıldılar ve sadece tatillerde hatırladılar. Oyunlar sadece senede 1-2 tören etkinliklerinin muhteşem bir dekorasyonu olarak görüldü, ancak spor oyunları olarak tanınmadı (Kalysh \& Asankanov, 2018: 37). Ota Asya halklarında yabani hayvanları yakalama ve evcilleştirme yöntemlerini ve tekniklerini yansıtan eskiden kalma yeni rekabet oyunları var. $\mathrm{Bu}$ nedenle, arkeolojik materyallerden bilinen boğa ile yapılan kült oyunlar, sığır yetiştiriciliği hayatında önemli bir rol oynamaya başladığında, ilkel toplumun gelişim aşaması ile genetik olarak ilişkilidir. 20. Yüzyılın başlarına hatta ortalarına kadar Orta Asya coğrafyasında ve özellikle Altay, Sayan ve Tanrı Dağları'nda çok sayıda yabani atlar olduğunu öğreniyoruz (Bronevskiy, 1830: 195; Toqtabay, 2010: 23-24). Çalışmada, kadim Türklerde yabani atları yakalama, şimdiki Orta Asya Türk halklarında ise kısmen yabani ama daha ziyade yarı yabani atları yakalamak ve onlara ilk defa eyer vurma oyunu anlatılacaktır. Türk dünyasında atlı oyunlarda başı çeken Kırgızlar, bu yabani atı yakalama oyununa; "Ukuruk-salmay" veya "Ukuruk-salmaktuu" demektedirler. Kazaklar ise buna benzer bir oyuna sadece "Qurık" demektedirler. Şor, Tuva, Hakas, Saka, Teleüt, Telengit, Çulum ve özellikle oyunun çok daha popüler olduğu Altay Türkleri ise "Emdik-ürediş" demektedirler. Bu terimin yanı sira "at tudaru" (at yakalama / at tutma) oyunu da denilmektedir.

Bugünlerde ise hiç yok denecek kadar yabani atların olmadığını, sadece Altay ve Sayan Dağları'nın kuytuları taygalarda nadiren olduklarını oralarda yaptığımız alan çalışmalarında öğreniyoruz. Yine bu coğrafyalarda yaşayan Türk halkları ihtiyacın çok üstünde at yetiştirmekteler. Söz konusu atları çekim, yükleti ve ulaşımdan ziyade beslenme ihtiyaçları için sahiplenmektedirler. Dolayısıyla bu atlar sürüler halinde serbest bir şekilde meralarda otlanmaktadırlar. Uzun süre baş1 boş dolaşan bu atları tamga vurmak, sağmak, şaman ayinlerinde kurban veya etini yemek, külük (yarış atı) ve yorga (rahvan) özelliği taşıyanları yakalayıp eğitip binmek vb. gereksinimlerden dolayı yılkı çobanları veya sayapkerler (at bakar / seyis) yakalamak isteyeceklerdir. En azından yarı yabani halde olan bu atları yakalamak, yabani atları yakalamak kadar zor olmaktadır. İşte o zaman Kırgızlar'ın “ukuruk", Kazaklar'ın "qurlk" ve Altaylar'ın "arkan" denen cisimler söz konusu atları yakalama işlevini yapmaktadır. Atlı göçebe kültürü ve ekonomik yaşam tarzının ortaya çıkardı̆̆ 1 bu at yakalama olayı, zamanla rekreasyonel ve eğlence unsuru ile atlı oyun ve yarışların bir paçası haline gelmiştir (Toqtabay, 2010: 19). Her kabile veya şahıslara ait olan bu at sürüleri çoğu zaman bir arada yaşarlar. Bu seyip (serbest) yayılan (otlanan) atların hangi şahsa veya hangi kabileye ait olduğunu 
anlamak için "tamga" vurulmaktadır. Her kabilenin kendisine ait sembolik işaret taşıyan tamgaları bulunmaktadır. $\mathrm{Bu}$ sembolik işaret mühür şeklinde bir demir plakaya işlenir ve $80-90 \mathrm{~cm}$ uzunluğunda bir demir ucuna monte edilir. Bu da bir ateş harında kızartılarak atın kalçasına (genelde sağ tarafi) basılır. Burada oluşan yanık tamga belli bir süre sonra iyileşir, at ölünceye kadar bu damga kalır ve sahibine aidiyet işlevini sürdürür. (Oynoshev \& Chochkina, 2016: 27).

Bu kısa tanımlardan yola çıkılacak olunursa, atın evcilleştirilmesi ve binek haline getirilmesi olayı, muhakkak ki, insanın at ile ilk temasından kaynaklanmaktadır. Dolayısıyla bu oyunun en azından tüm atlı oyunlar içerisinde en eski ve köklü tarihi olduğu rahatlıkla söylenebilir. Bu cevap aynı zamanda ukuruk salmay oyununu ilk defa hangi klan veya toplum oynadı sorusunu karşımıza çıarır. Bu soruya mantıki olarak "atı kimler ilk olarak evcilleştirdi ise o klan veya toplum bu oyunu ilk olarak oynamıştır" cevabını rahatlıkla verdirebilir. Fakat "atı hangi klan veya toplum evcilleştirdi" sorusu hala Hippoloji, antropoloji, arkeoloji, kültür - tarihi bilimcileri tarafindan netleştirilememiştir. Bu konuda son zamanlarda yapılan araştırmalar Türk - Moğol halklarını ön plana çıkarsa da (Levine, 1998: 76), buna antitez sunan çalışmalar da bulunmaktadır (Jansen, et al. 2002: 10909). Türk medeniyet ve kültürünün inkişafını iki unsura bağlanır, bu atın ehlileştirilmesi ve demiri kullanmayı başarabilmedir (Kafesoğlu, 2007: 220-226). Ek olarak, binicilik sporunun gelişim tarihi, Botai istasyonunun yakınındaki Akmola bölgesinde düzenlenen eski atların iskeletleriyle yapılan kazılarda birçok değerli buluntuyla doğrulanmaktadır. Bu kazıların araştırmacıları, bu mezarların varlığını MÖ 6. binyıla bağlamaktadır. Bu kazı resmen "Botai kültürü" adını verdi. Botai kültürünün özelliği, kazıların Altay Kazak bozkırlarında vahşi atların evcilleştirilmesi ve Türklerin ataları tarafından vahşi atların kullanımı hakkında benzersiz bilgi kaynakları olmasıdır (Olsen, 2003: 85). Böyle bir açıklama ile sporun kökeni temel olarak üretici güçlerin gelişimi ile bağlantılıdır.

Küresel spor sisteminin özel bir parçası olarak geleneksel sporlar ve oyunlar, eski, egzotik ve nesli tükenmekte olan kültürel tezahürler kavramına yol açabilir, ancak bir dereceye kadar, son derece yaygin ve ilginç bir alt grup sporun sadece dış görünüşüdür. Sosyolojik, antropolojik veya kültürel bilimlerle ilgili farklı bakış açılarından analiz edilebilir. Aşağıda kısaca açıklanan bu perspektifler ya kültürel çalışmalar ya da spor antropolojisi olarak daha geniş bir araştırma alanıdır ya da habitus, kolektif hafiza ya da hafiza siteleri gibi belirli kavramlar ve modellerdir. Bu yaklaşımlar ve geleneksel oyunlar ve sporun kendisi, geleneksel spor oyunlarının kişisel, yerel, bölgesel ve hatta ulusal düzeyde rolüne ilişkin ana nokta gibi görünen kimlik süreçleriyle kolayca ilişkilendirilebilir. Bilindiği gibi günümüz Türk dünyasında at sürüsüne yılkı denilmektedir. Göktürk abidelerde atlar çoğul anlamında kullanılmak istenildiğinde yapı olarak tekil olan ama anlam olarak çoğulu ifade eden ve topluluk ismi olarak kullanılan yllkı kelimesi tercih edilir. "Yllkr[sin ...] süsi tirilip kelti." (BK. D. 39), "Kül Tigining altunın kümüşsin ağışın barımın tör[t bing?] yllk[ls]ın Tuygut bu..."(KT. GB. 1)", "Tangut budunug bozdum. Oglin yo[tuz]ln yılkisin bartmin anda altım." (BK. D. 24), "Türk budun aç erti. Ol yılkıg alıp igit [t] im." (BK. D. 38) cümlelerinde geçen yılkı kelimesinin anlamını Ergin söz diziminde "yllkl, at sürüsü; hayvan, hayvan sürüsü", "at sürüsü, yllkı" olarak vermiştir (Tekin, 2010:151,188, 894). Demir'e göre (y)11- (inmek) fiilinden +k1 yapım ekiyle türeyen bu kelime; "başlangıçta kelime genel olarak dört bacaklı hayvanları karşılamaktadır. Zamanla daha özele indirilerek evcilleştirilebilen at, koyun, sığır ve bunların sürüleri için kullanılmıştır (Demir, 2001: 538-541). Sporun tarihi, muhtemelen, insanların aktif varlıklar olarak var oluşları kadar uzağa uzanır. Spor, insanların doğa ve çevre konusundaki ustalıklarını arttırmaları için yararlı bir yol olmuştur. Bazı spor dallarının kökenleri veya ortaya çıkışları konusunda tartışmalar bulunmaktadır. Özellikle Türklerde spor ve oyun kültürü çok yaygın idi. Bu Asurlar, Etiler ve Hititlerden yani ön Asya uygarlıklarından itibaren gelişerek devam etmiştir.

\section{Amaç}

Bilindiği gibi küreselleşe tazyikleri hemen hergün özellikle azgelişmiş veya gelişmekte olan ulus ya da azınlıkların milli kültür halkasından birini koparıp gitmekte, bundan kendisine düşen payı 
geleneksel spor oyunları da fazlasıyla nasibini almıştır. Dolayısıyla geleneksel spor oyunlarının büyük bir kısmı unutulmuş, bir okadarı unutulmaya yüz tutmuş ve bu konuda çalışma alanı git gide daralmıştır. Ancak Sovyetler Birliğinin yüz tumasından itibaren başta Altay Türklerinden Telengitliler derneğinin başlattıkları "El-oyunları", Sovyetlar dağıldıktan sonra Kazan Tatarları ile Başkurtların "Saban-toyu, bunların ardından Kırgızistan Issık-köl'de 2014 yılında başlatılan "Dünya Göçmen Oyunaları" söz konusu oyunlara canlılık getirmiş, popülaritesini artırmış, asırlardır milli kimlliğini yirirme endişesi taşıyan halklarda kısmende olsa bu endişeleri gitmiş ve özgüven gelmiş, dahada önemlisi asırlardır birbiriyle kapuk yaşayan kardeş halkların oyular sebebiyle bir araya gelerek aynı millet olma şuuru uyuyan hücreler gibi uyanmıştır.

Tabiiki burada tüm bu geleneksel spor oyunları ve bu oyunların yapıldığı organizasyonların küresel düzeyde tanınmasına, canlanmasına ve diğer kültürlere tanıtılmasına, unutulmuş unutulmaya yüz tumuş oyunların yenden gün yüzüne çıkarılmasına, özellikle 2013-14 yıllarından bu tarafa "Dünya Etnospor Konfederasyonu"nun büyük katkılarını; bu aziz millete mensubiyet şuuru duyan hiçbir kimsenin gözardı etmesi mümkün değildir. Bu mütevazi çalışmada Türk halklarının Orta Asya bozkırlarında yabani ve yarı yabani atları yakalayarak ehlileştirme eyleminden kaynaklanan geleneksel atlı sporların araştırılması; orijinal adları, kural ve kaideleri ile ritüellerinin kaybolan yönlerinin ortaya çıkarılması, tarihi süreşçte geçirdiği dönüşümlerin belirlenmesi, oyunun kendi yeri, kendi doğası ve kendi karakterinde izleyip gün yüzüne çıkarmak, Türk ve dünya spor literatürüne kazandırabilmek amaçlanmıştır.

\section{Metot}

Bu çalışma, projeden üretildiği için yazılı kaynaklara yapılacak atıflardan ziyade, gözlemlere dayalı betimsel araştırma ile karşılaştırma, bu çalışma yönteminin merkezine alınmıştır. Zira söz konusu olacak oyun, kendi karakterinde, kendi yapıldığı coğrafyalarda ve kendi yerinde bizzat izlenip gözlemlenmiştir. Saha çalışması çerçevesinde yapılan bu çalışma, Orta Asya Türk halkları ve yaşadıkları coğrafya ile sınırlandırılmıştır.

\section{Tartışma ve Sonuç}

Ukuruk Salmay / Salmaktuu: Kırgız Türkçesi’nde ukuruk, "yabani veya yarı yabani at sürüsünden bir at yakalamak için üzerinde ilmekli kemendi olan uzun sırık" a denilmektedir. Bu sırık yaklaşık 5-7 metre uzunluğunda olmaktadır (Yudahin, 1994:781). Kırgız Türkçesi’nde salmay ve salmaktuu'nu kelime karşıllğı; salmak, atmak, sallamak, yakalamak için salmak anlamına gelmektedir. Ayrıca sözlüklerde ise, ă̆ır çeken, ă̆ır; iş salmaktuu boldu: iş ciddi/ güç bir şekilde döküldü ve ayn zamanda ciddi ve müsbet adam anlamına gelmektedir (Yudahin, 1994: 634). Ukuruk salmay yarışı, yabani veya şimdilerde olduğu gibi yarı yabani yetişkin atları adı geçen sırıkla yakalama yarışına denilmektedir. 3-5 yılkı çobanları bir araya geldiğinde, her çoban kendi yılkı sürüsü içinden semiz, tüyleri parlayan, başı dik, yerinde duramayıp sürekli sağa - sola koşup zıplayan, diğer aygırla saldırarak sindirmiş dominant bir aygırı seçerler. Çobanlar kendi sürüsünden seçtiği ata ile yarışamaz, diğer yılkı sürüsünün çobanı ancak yakalama yarışına katılabilmektedir. Her çoban diğer yılkı sürüsü çobanının seçtiği atla yarışmaktadır. Sonra çobanların hepsi birden

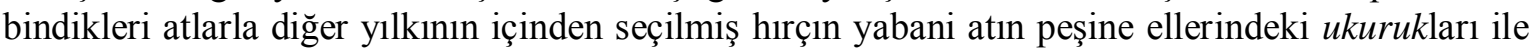
birlikte düşerler (Resim 1). Kim önce ukuruk salıp atı yakalar, üzerine binip durabilir, sakinleştir ve $\mathrm{o}$ ata bundan böyle eyer vurulacağını kabullendirebilir ise oyunun galibi sayılmaktadır. Bu oyunu Moğollarda oynamaktalar (Resim 2). Ukuruk-salmay oyununda kullanılan at yakalama tekniğinin benzeri olan (5-7 m sırık olmadan) kement atma tekniğinin Tarihi Türk devletleri savaşlarında düşmanı veya düşmanın atını yere düşürerek etkisiz hala getirmek için de kullanılmıştır. Bunun bir savaş tekniğine dönüştüğüne Doğuda oluğu gibi Batı Türk devletlerinde de rastlanılmaktadır. Aynı şekilde at yakalama oyun tarzını 12 yüzyıl Harezmşahlar'da görmekteyiz (Resim 3). 


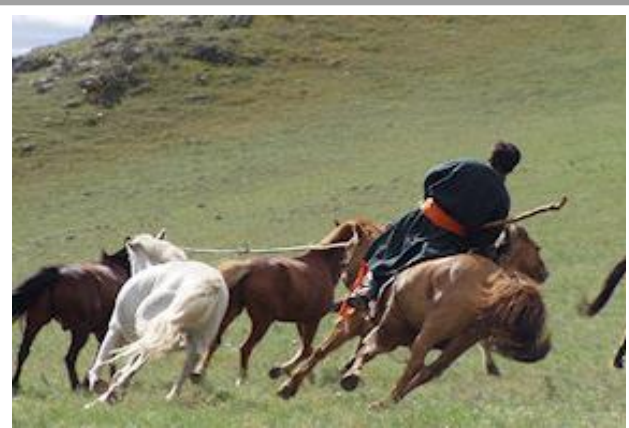

Resim 1: Ukuruk salmay yarış1

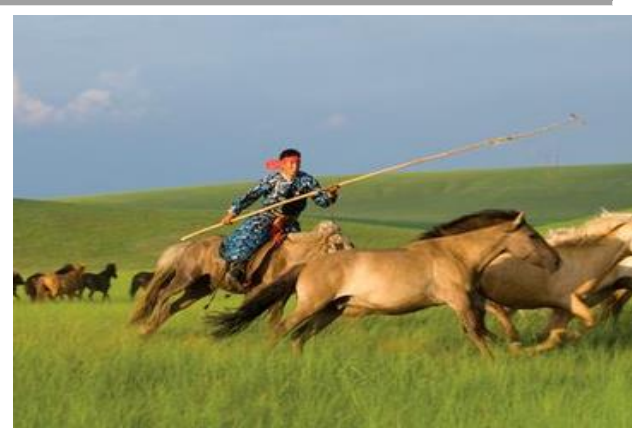

Resim 2: Ukuruk salmay yarıș1

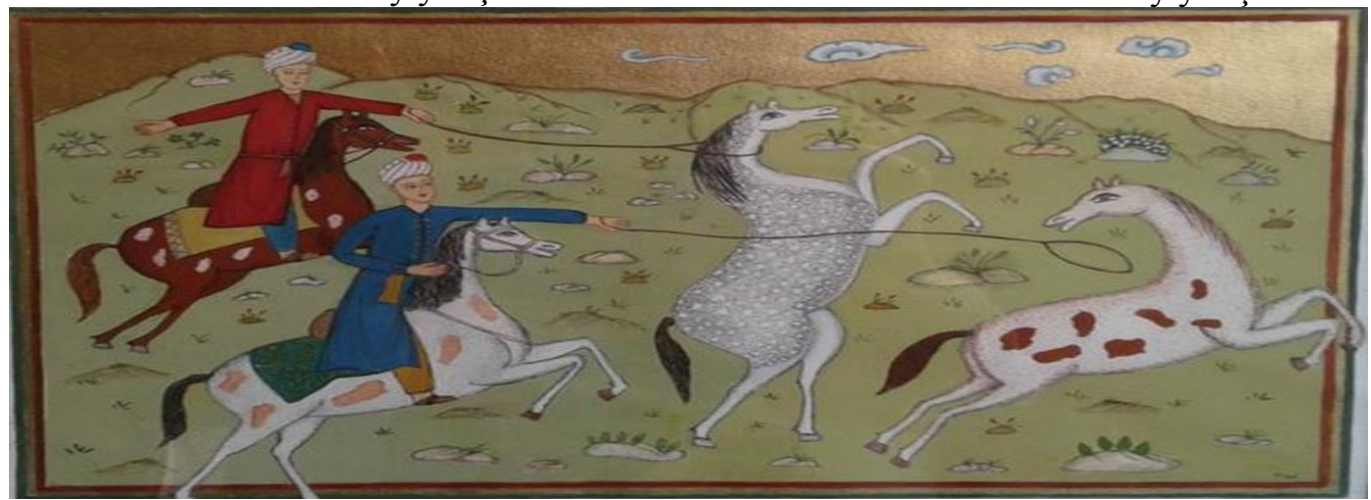

Resim 3: Ukuruk salmay, Hive, Harzemşahlar 1182

Qurık / Sırık Jalgan (2-3 yaş taya ilk yular takma ve eyer koyma yarışı): Kazalarda "qurık" kelimesi Kırgızca'da "ukuruk" kelimesinde olduğu gibi "5-6 metre uzunluğunda, ucunda ilmekli urganı olan uzun sırık" anlamındadır (Koç ve ark.2014: 216). Karaçay- Malkar Türkçesi’nde Üyür: aygır iadesindeki vahşi at sürüsü; Üyürsüne: evcilleşmek-yakınlık duymak, alışmakyakınlaşmak; Üyürsündür: evcilleştirmek- alıştırmak- yakınlaştırmak anlamlarına gelmektedir (Tavkul, 2000: 424). Hiç eğer vurulmamış iki yaşındaki tayları evcil bir at sırtında kovalayarak, bu sırığı uzatarak ucundaki ilmeği o iki yaşındaki tayın boynuna geçirilir, sonra yakalanan taya bir veya iki kişinin yardımıyla zoraki eyer vurulur, tayı yakalayan genç tayın sırtına binmektedir. Binilen tay binicisini üzerinden atmak için büyük hırçınlık içinde sağa-sola, öne-arkaya debelenir veya sıçrar. Eğer binici 3-5 dakika dayanabilir ise, tay yavaş yavaş sakinleşmektedir (Divaev, 1907: 346-47). Atın evcilleştirilmesi ve insanlık hizmetine sunulması, çok ileri düzeyde bir inkişaf olduğu için hangi topluma, hangi millete veya hangi medeniyete ait olduğu bilim insanları tarafindan 20. Yüzyılın ortalarından itibaren en çok tartışılan konulardan birisidir. Bu bağlamda eski ve köklü medeniyetlerin hemen hepsi kendi etnitesine maletme temayülündedirler. Her alanda olduğu gibi bu konuda da batı dünyası ve Rus araştırmacılar Antik Grekleri öne çıkarmakta ve bu görüşlerini dogmatikleştirmek için büyük çaba sarf etmektedirler (Ackland, et al. 2007: 8715). Oysa hikâye, olguların ve tespit edilen delillerin seçimi meşrulaş̧ırmama engeliyle karşı karşıyadır. Kaldı ki batı dünyasında küçümsenemeyecek bir objektif entelektüel kesim (arkeoloji, kültür tarihçileri, antropoloji vb.) atın evcilleştirilmesi olayını tatmin edici bir şekilde Türk-Moğol halklarına mal etmektedirler (Levine, 1998: 77; Zaibert, 1993: 27).

Göçebeler yaylada yerleştikten 3-5 gün sonar, kısrakların sağım yerleri belirlenir, kulunların bağlandıkları 'cele / arkan' yere çakılır. Bu zamana kadar küçük kulunlar biraz daha güçlenirler ve kendilerini daha iyi hissederler. Yayladaki genç çocuklar sürekli olarak atların kaldıkları çadırlardan uzak steplere doğru gitmemeleri kontrol ederler. Daha büyük delikanlılar 'yiğitler' ukuruklarıyla inatçı tayları - 'kulunları' yakalamaya çalışırlar. Ukuruğu boynuna geçirdikten sonra kulunun 
kafasına "nokto / cılbır" - (kgz) - "yular" (tur) geçirip ve onun yardımıyla celeye bağlanır. Tüm kulunlar bağlandıktan sonra kısrakları sağan genç kadınlar nineleri ile birlikte gelier ve celeye yakın bir yerde zengin ve ritüel bir sofra hazırlıklarına başlarlar. Büyükanneler eskiden beri kalan bazı ritüelleri yerine getiriyorlar, bunlar: çelenin bağlandığı kazıkların üzerine süt veya ayran döküyorlar ve kulunların alınlarını da onunla yağlıyorlar. Eski - yaşlı insanlar iyi dileklerini söylüyorlar. $\mathrm{Bu}$ ritüeller ve yemekler bittikten sonra genç delikanlılar ve güçlü yiğitler, genç inatçı (yani daha önce hiç eğitilmemiş) tayları (tay-kunan - 3 yıllık tay veya kunan) yakalayıp eğitmeye başlıyorlar. Yine aynı şekilde yiğitler tayları yakalayıp, güç ve kuvvet kullanarak zorla üzerine eyer geçiriyorlar (eyerlemek). İlk olarak çok tecrübeli, kuvvetli ve kendine güvenen bir yiğit oturuyor üzerine. Daha önce üzerine kimseyi bindirmemiş, eğitilmemiş tay (kunan) binicisini her türlü üzerinden atmaya çalışır, zıplar, yere kendini düşürür vs. Yiğit de atın eyerinden yere düşmemek ve sağlam durmak için elinden geleni yapmaya çalışır. Daha bundan 80-90 yıl önce oyun Sibirya Türk halklarından Tuvalar iki dönem devlet olmuştur. Bu iki dönemde de devlet armalarını Emdik Ürediş (ukuruk salmay) oyununu yapmışlardır (Resim 4 ve 5).

Seyirciler açısından gençlerin ustalık ve kuvvet göstergesi müthiş bir görüntü sergiliyor. Yarı yabani atların eğitmesi herkesin becerebileceği bir şey değildir. Çok az sayıda gençler ancak bunu başarabilmişlerdir. Maalesef bu enteresan adet şimdilerde unutuluyor. Günümüzde çok az köylerde ancak nadir gençler bu eski atalardan kalan at eyerleme (qurık) geleneğini devam ettirmeye çalışıyor.

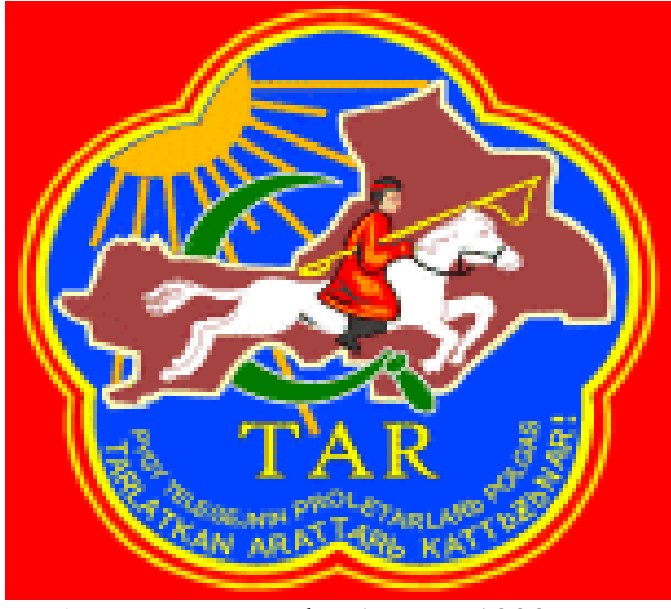

Resim 4: Tuva Devlet Arması 1933-1939

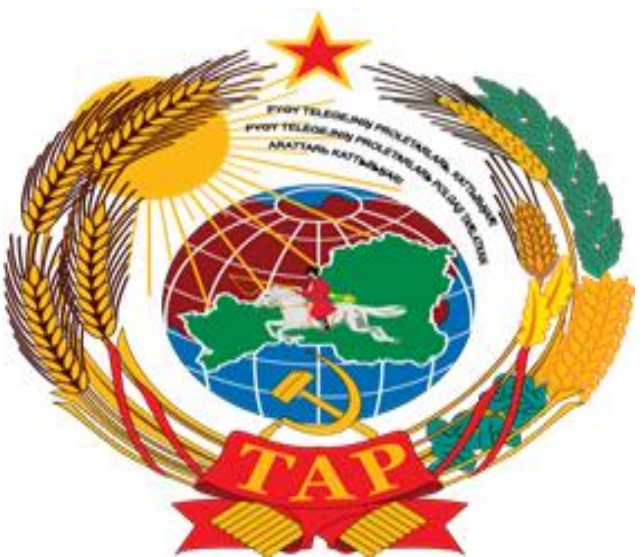

Resim 5: Tuva Devlet Armasi 1940-1944

Emdik Ürediş (yabani atları yakalama, eyer ve gem vurup üzerine binme yarışı): Emdik: Altay Türk halklarında yabani veya yarı yabani ata, ayrıca üzerine daha önce hiç eyer vurulmamış ve gem takılmamış ata ve 2-3 yaşındaki taya (kunan) denilmektedir. Ürediş ise; eğitmek, öğretmek, üretmek, âtıl durumdan işlevsel hale getirmek anlamlarına gelmektedir. Emdik Ürediş, Sibirya Türk halklarında ve özellikle Altay Türklerinde popüler bir üçer kişilik atlı takım oyundur. Ayrica 1988 'den bu tarafa iki yılda bir Altay Cumhuriyeti'nde yapılmakta olan "El-Oyun" bayramının en önemli oyunudur. Bu oyuna "Altay'ın Rodio"su da denilmektedir (Oynoshev \& Chochkina, 2016: 49). Ancak bu oyunun 19. Yüzyılın sonu ve 20. Yüzyılın başlarında bu tarzıyla değil de şimdi Kırgızlar'da olduğu gibi ukuruk salmay usulü olduğu görülmektedir (Sımakov, 1984: 38). Emdik Ürediş'te atı yakalamak için kullanılan cisim, ukuruk salmay ve qurık 'ta kullanıldığ 1 gibi 5-6 metre uzunluğundaki ağaç sırıklar kullanılmamakta, bunun yerine rodeo da olduğu gibi ucu ilmekli arkan (urgan) kullanılmaktadır (Resim 6). Önceden belirtildiği gibi oyun, Sibirya coğrafyası Türk halklarında oynanmaktadır. Rusya Federasyonu'na bağlı Sibirya coğrafyada yaşayan Türk 
halkları Tuva, Altay, Dağlık Altay, Hakasya ve Yakudistan Cumhuriyetleri olsun hepsinde oldukça azınlık durumundadırlar (Yiğit, 2012: 27-28). Buna rağmen adı geçen coğrafyalarda çoğunluklar bu oyunu oynamazlarken Şorlar, Teleüt, Telengit, Çulum, Dolgan gibi ana dillerini unutmakta olanlar dahil tüm Türk halkları emdik-ürediş yarışını ve bunun arkaik tipi olan ukuruk salmay ile qurık oyunlarını oynamaktadırlar.

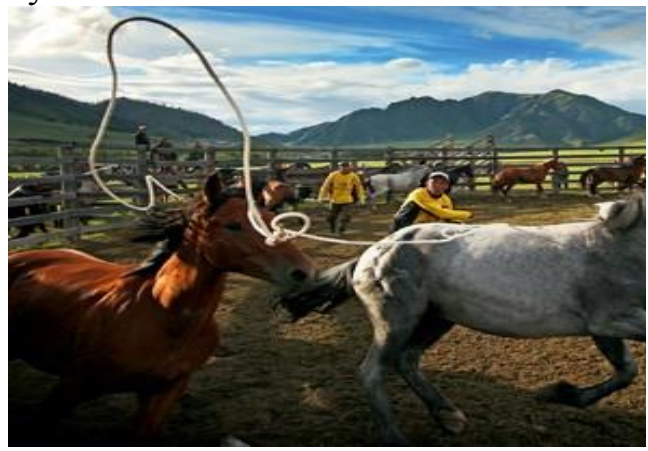

Resim 6: Emdik-ürediş, Altay

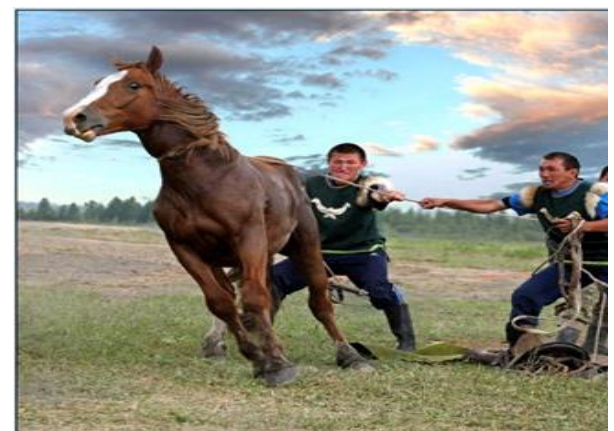

Resim 7. Emdik-ürediş, Altay

Emdik-ürediş oyun şekli: İlk önce dağlarda veya meralarda seyip (serbest / başıboş) yayılan (otlanan) atları yılkı çobanları ıslık ve gırtlaktan çıkardıkları karışık ve anlamsız yüksek seslerle dağınık halden toplu hale getirmeye çalışırlar. Y1lkı çobanları veya sayapkerler (seyisler / at bakar) tüm bu eylemleri kendi bindikleri atların üzerinde gerçekleştirirler. Yine benzeri sesleri çıkararak bu bir nevi yabanileşmiş atlardan 30-50 kadarını (o anda ne kadarını toplamışlar ise) daha önceden etrafı çitler ile çevrilip hazırlanmış olan alana $(a \breve{g} l l)$ girdirirler. Bu alan veya Sibirya Türkleri'nin deyimiyle "ağll" veya "ber" aynı zamanda yarış alanıdır (Resim 7). Yarışacak takım en az 19 yaşını doldurmuş üçer kişilik erkeklerden oluşur. Takımların sayısında bir sınırlama olmaz ve yarış alanına at sokmuş her takım yarışabilmektedir. Ancak yarışacak takımın kaptanı veya yılkı sürüsünün sahibi en az 30 gün önceden tertip komitesine yarışa iştirak edeceklerini bildirmesi gerekmektedir. Çünkü katılımc1 sayısına göre yarış alanı tahsis edilip çitlerle çevrilecektir. Atların sokulduğu çitlerle çevrili alana 2030 metre mesafeye, 3-5 metre yüksekliğinde ve yedi veya dokuz boğum (kertik) oyulmuş ağaçtan direkler (terek) dikilmektedir (Resim 8). "Kök-terek", "altın-terek" veya "at-tereği' de denilen bu direklerin başı, çoğu zaman halk arasında öğretim almadan usta-çırak ilişkisiyle özel yetişmiş sanatçılar tarafından at başı veya kartal şeklinde bir heykeltıraş gibi oymaktadırlar. Önce hakemler tarafından kura çekilip takımların sıralaması belirlenir. Takımlar sırasıyla alan içine alınır. Alana giren üç kişilik takımdan birinin elinde ucu dügümmlü kement (urgan / arkan) bulunmaktadır. Kementi rastgele bir atın boynuna geçirmek için firlatılır. Bu esnada atlar çevrili alan içerisinde oraya-buraya kaçışmaktadırlar. Kement bir atın boynuna geçmiş ise, bu defa kemendi geçiren kişiyle birlikte takımdaki diğer iki kişide atı zapt etmek için hemen kementten tutarak dışarıda dikili direğe sürükleyip bağlarlar. Bu esnada iki kişi atı tutar ve diğeri de atı eyerlemeye çalışır. Atın eyerlenmesini ağzına gem takılması takip eder ve gem takıldığında atın yakalamak için boynuna geçirilmiş kement çıkarılır. Takımdan ata gem takan ve yulardan tutan yarışmacı, bu ata binerek atı sürmeye çalışmaktadır. Atı kementle yakalama, atın üzerine eyer koyma ve ağzına gem takmak çok zor olsa da yarışın en zor kısmı ata bindikten sonra atın yorulup sakinleşmesine kadar üzerinde durmaktır. Çünkü binildikten sonra at sürekli sağa - sola sıçramakta ve bineni düşürmek için var gücüyle hırçın bir şekilde debelenmektedir. Bazen takımlar yarışın etapları esnasında atı hizaya getiremeyip yarışı terk ettikleri olmaktadır.

Emdik ürediş yarışı zamana karşı yapılmaktadır. Hangi takım yukardaki aşamaları en kısa sürede tamamlar ise yarışın galibi olmaktadır. Yarışta ilk üçe giren takıma ödül veya ödüller verilmektedir. Yarışlar resmi bayram veya organizasyonlarda yapılmış ise ödül olarak nakdi para, eğer özel toylarda veya mahalli düzeyde yapılmış ise canlı ve erkek hayvan verilmektedir. Emdik- 
ürediş Latin rodeolarına benzeyip daha iptidai bir görüntü sergilese de, rodeo atları aslında ne yabani nede yarı yabanidir, tamamen evcildirler. Fakat eyeri paldon'a bağlayan terkibağ $ı$ ile uzantılı batıcı özelliği olan bir sicim atın kuyruk altından ve iki kalçalarının arasından geçirilerek döş-kolanı'na bağlanmaktadır. Bu bağlama işlemi, at sahaya çıkacağı an sağl1-sollu ve önlü-arkalı bir demir kafese sıkıştırılarak yapılmaktadır. Bu batıcı sicimlerle ve üzerinde binicisiyle sahaya çıkan at, aşırı derecede huysuzlanarak yeni eyer vurulmuş bir at gibi var gücüyle binicisini üzerinden atmaya çalışmaktadır. Rodeoda atın huysuzluğu binicisine değil kalçası arasından geçen batıcı sicimleredir. Dolayısıyla emdik-ürediş doğal, rodeo suni bir yarıştır.

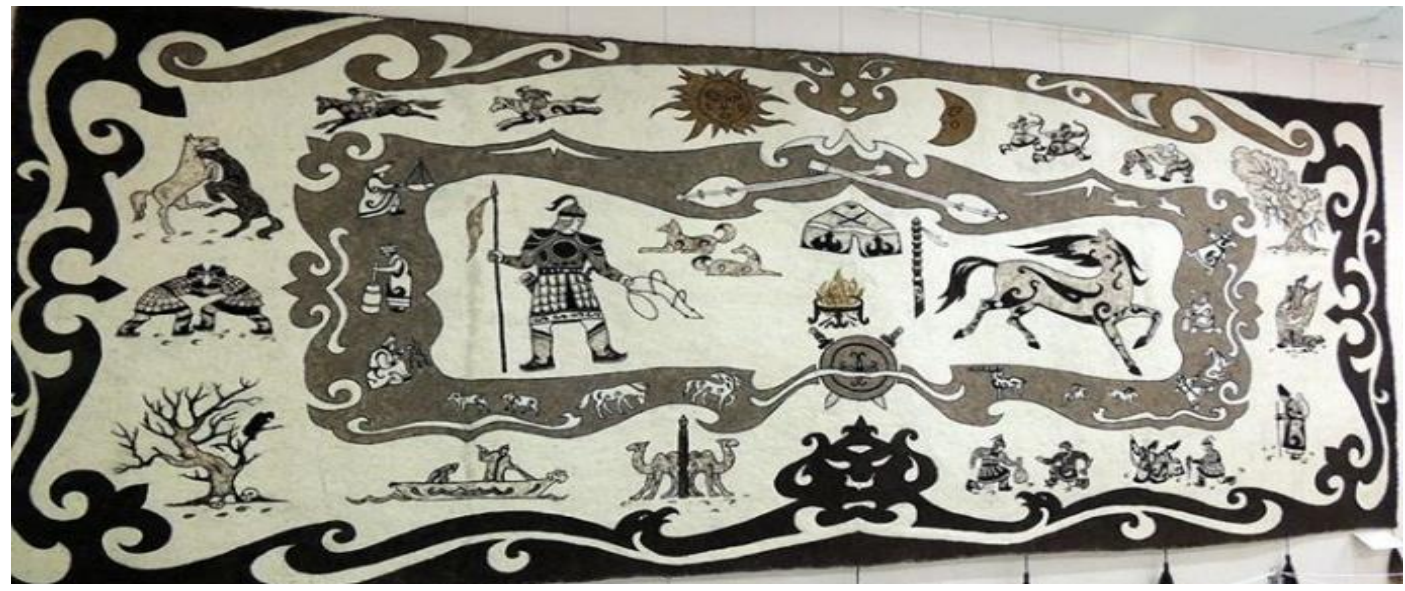

Resim 8: Altay “El-Oyun" 2018'in Afişi; ortadaki Emdik-ürediş direği, onun önündeki atı, sol tarafta yarışçı ve elinde yakalanan atın ağzına takılmak için gem-yular takımı

\section{Sonuç ve Öneriler}

Monografimizin konusu atın evcilleştirilmesini araştırmak olmasa da söz konusu bu üç oyunda direk atın evcilleştirilmesiyle direk ilintilidir. Binicilik insan ve atın birlikteliği, birbirleri ile bütünleşmeleri üzerine kurulmuş bir ortak yaşam disiplinidir. Bu bütünleşmenin en kesin şekilde tecrübe edildiği alan ilk önce Ukuruk - salmay, ikinci aşama Qurık ve üçüncü aşama Emdik- ürediş olarak görülmektedir. Zira birbirinin versiyonu olan bu üç oyun insanoğlunun at ile ilk temasından kaynaklanmaktadır. Son yıllarda atın evcilleştirilmesi ile ilgili yapılan araştırmaların Botai kültürünü ortaya çıkarmasıyla birlikte ibreleri Türk- Moğol halklarına çevirmiştir. Fakat bu gibi ciddi ve çok sayıda araştırma bulunsa da atın hangi tarihlerde ve hangi klan veya toplum tarafından ehlileştirildiği henüz netleşmiş gözükmemektedir. Ancak atı evcilleştirmeden, onu çekim, yükleti ve en önemlisi ulaşım için binit haline getirilmeden çok önce onu yakalamak, uslandırmak ve insana yakın hale getirmek gerektiği aşikardır. İşte tam da bu aşamada birbirinin versiyonu olan bu üç oyun (ukuruk salmay - qurık - emdik ürediş) atı evcilleştirme aşamasında ortaya çıkmış olduğu muhakkak ve müşahhastır. Türk halklarının Altay, Sayan ve Tanrı dağları ile diğer Asya steplerinin çetin coğrafyasında zorlu göçebe yaşamını sürdürürlerken at, bu yaşam tarzının mobil aracı olmuştur. Ata çok önem vermeleri ve çok sayıda at sahibi olmaları bu ilkel oyunların sürekliliğini mecbur kılmıştır. İlk önce bozkır iktisadi hayatın zorunlu gereksinimi olarak ortaya çıan bu oyunlar, Kement Atma tekniğini geliştirip savaşlarda düşmanı ve düşmanın atını etkisiz hale getirerek bir savaş aracı olarak kullanmışlardır. Zamanla Ukuruk-salmay ve Qurık gibi oyunlar eğlence unsurunun bir aracı olmuş, daha sonra da Emdik-ürediş gibi kazanmak, muktedir almak arzusu ile belli kurallara bağlanarak oyun olayından spor formatına doğru bir geçiş sağlamıştır. Orta Asya Türk halklarında çok engin bir tarihe sahip olan ve günümüzde kırsal bölgelerde çok nadiren yapıldığı anlaşılan Ukuruk-salmay ve Qurık oyunları, artık unutulmaya yüz tutmuş oyunlar arasında bulunmaktadır. 
Türk halklarının bu at yakalama oyunlarının gün geçtikçe küreselleşmeden dolayı olumsuz etkilenmektedir. Oyunun Güney Sibirya Türk halklarında olduğu gibi popüler hale gelmesi için Merkezi Asya genel ve özel toylarında da sergilenmelidir. Bilimsel olarak pedagojik önemi ve yeni nesillere kendi kültürel rolü ve yeri tanıtılmalı, oyunlarının eğitim sürecindeki etkililiği teorik bakımdan tahlil edilmesi ve pratik olarak uygulanması önerilir.

\section{KAYNAKÇA}

Ackland, GJ, Signitzer M, Stratford K, Cohen MH. (2007). "Cultural hitchhiking on the wave of advance of beneficial technologies”. Proc Natl Acad Sci USA 104: 8714-8719

Arstanbek, Kasen (2004). Kırgızskie ıgrı i razvleçenya, Bişkek: İlim

Arvas, A., Yılmaz TD., Zengin Z. (2017). “'At Çabış’ Bir Oyun mu? (Bir Örneklem Olarak Kırgız Türklerinin Destanları)”. Motif Akademi Halkbilimi Dergisi. Cilt: 10, Sayı: 19: 1-14.

Belek, K. (2015). “Türk Kültüründe At ve Çağdaş Atçılık: Dünden Bugüne Kırgız Kültürel Hayatı Örneği”, Gazi Türkiyat, Sayı: 16, ss. 111-128.

Bronevskiy, S. (1830). "Zapiski o kirgiz-kaysakakh Sredney ordy”, Otechestvennyye zapiski, Chast' 43, Sankt-Peterburg, 194-285

Demir, N. (2001). "Y1lk1 Kelimesi Üzerine”, Türk Dili, Say1 593: 538-541

Divaev, AA. (1905). Igry kirgizskikh detey [Kırgız çocuk oyunları], Turgayskaya gazeta [Turgay gazetesi]. 1905, 13 noyab / Kasim, 4-9

Divaev, AA. (1907). "Drevniye igry kirgizskoy molodezhi [Kırgız gençliğinin antik oyunları]", Turkestanskiye vedomosti [Türkistan Gazetesi], №54: 346-547.

Erdem, M. (2005).Kırgız Türkleri, Dinì ve Sosyal Hayat, Türkiye Diyanet Vakfı Yayınları, Ankara

Gedin, S. (1899). V serdtse Azii. Pamir, Tibet, Vostochnyj Turkestan. V 2-kh tomakh. Tom 1. SanktPeterburg: İzdaniye A.F. Devriyena

Groll, Michael - Malgorzata B. and Jorma S. (2015). "Cultural aspects of Traditional Sports and Games", Recall: Games of the Past- Sports for Today, ResearchGate, Article (PDF Available) June 2015 with 149 Reads:1-14

Gülbeyaz, K. (2008). “Millì Kırgız Dügünü”, Akademik Bakış Uluslararası Hakemli Sosyal Bilimler E-Dergisi, Calalabad, 15

Jansen T, et al. (2002) Mitochondrial DNA and the origins of the domestic horse. Proc Natl Acad Sci USA 99: 10905-10910

Jarvie, G. (2006) Sport, culture and society. An introduction, , London \& New York: Routledge

Kafesoğlu, İ. (2007) Türk Milli Kültürü. İstanbul: Özener Matbaası.

Kalysh, Ав. \& Asankanov, A. (2018). Traditional horseracing and sport games of Kazakhs and Kirghiz in the 19th and the beginning of 20th centuries”, Journal of history. №1 (88): 36-42

Kaya, D., (2005). “Kırgızlar’ın Millî Oyunu Kökbörü”, İzzet Gündağ Kayaoğlu Hatıra Kitabı Makaleler, İstanbul, : 303-313

Koç, K., A. Bayniyazov, V. Başkapan (2014) Kazak Türkçesi - Türkiye Türkçesi Sözlüğü, Muğla: Anatolia Kitabevi 
Levine, MA. (1998) "Botai and the Origins of Horse Domestication", Journal of Anthropological Archaeology, Vol. 18, July 1998. DOI: 10.1006/jaar.1998.0332: 29-78

Olsen, Sandra L. - Grant, S. - Choyke, A. and Bartosiewicz, L. (2006). Horses and Humans: The Evolution of the Human-Equine Relationship. Oxford: BAR, International Series 1560:375

Olsen, SL. (2003). The exploitation of horses at Botai, Kazakhstan. In M. Levine, C. Renfrew and K. Boyle (eds.), Prehistoric Steppe Adaptation and the Horse. McDonald Institute Monographs. Cambridge: McDonald Institute for Archaeological Research, : 83-104

Oynoshev, VP. \& Chochkina, MP. (2016). Altay oyundar = Altayskiye narodnyye igry [Altay Oyunlar1 = Aktay Halk Oyunlar1], Gorno-Altaisk: PE Orekhov AV.

Ögel, B. (2001) Türk Kültürünün Gelişme Çağları. İstanbul: Türk Dünyası Araştırmaları Vakfı.

Ögel, B. (2003) Türk Mitolojisi I. Ankara: Türk Tarih Kurumu Basımevi

Simakov, GI. (1984). Obshchestvennyye funktsii kirgizskikh narodnykh razvlecheniy $v$ kontse XIX $v$. - nachale XX v. Leningrad: Nauka

Tavkul, U. (2000). Karaçay - Malkar Sözlüğü, Ankara: AKDTYK - TDK Yayınları: 770

Tekin, T. (2010) Orhon Yazıtları, 4. bs., Ankara: AKDTYK - TDK Yayınları

Toqtabay, AW. (2010). Qazaq jılqısınıñ tarïxı [Kazakların At Tarihi]. Almatı: Almatıkitap baspası

Türkmen M. İmamoğlu, O. Ziyagil M.A. (2006).” Popularity of the Wrestling sport in Turkey and it's comparison with the selected sports", Researches About The Turks All Around The World,163: 77-94

Uluışık, YP., Kara M. (2018). “Türk Destanlarındaki Toy Geleneğinde At Yarışı: Hakas Destanı Altın Taycı Örneği”, DOI: 10.7816 /idil-07-42-01, İdil, 7- (42): 99-105

Warmuth, V. - Eriksson A. - Bower Am. - Barker G. - Barrett E. - Hanks Bk. - Li Sh. Lomitashvili D. - Ochir-Goryaeva M. - Sizonov GV.- Soyonov V. And Manica A. (2012). "Reconstructing the origin and spread of horse domestication in the Eurasian steppe", PNAS, May 22, 2012109 (21) 8202-8206 pp; https://doi.org/10.1073/pnas.1111122109

Yiğit, A. (2012) "Rusya Federasyonu'nda Yaşayan Türk Topluluklarının Anadillerini Kullanma Oranlarındaki Bölgesel Farklılıklar", e-Journal of New World Sciences Academy - NWSANature Sciences, 4A0047, 7, (2): 16-34

Yudahin, KK. (1994) Kırgız Sözlüğ̈̈, 3. Baskı, Cilt I, Çev. Abdullah Taymas, Ankara: TDK Yayınları: 93

Yudahin, KK. (1994) Kırgız Sözlügü̈, 3. Bask1, Cilt II, Çev. Abdullah Taymas, Ankara: TDK Yayınları: 121

Zaibert, VF. (1993) The Eneolithic of the Ural-Irtish Interfluve [Ene-olit Uralo-Irtishskovo Mezhdurech'ya]. Republic of Kazakhstan, Petropavlovsk: Acad-emy of Sciences

NOT: Bu çalışma, KTMU-BAB-2018.GOSAUM.01 nolu, "Kırgızistan ve Türkiye'de Geleneksel Atlı Sporların Araştırılması” başıklı projeden üretilmiștir. 